\title{
A Comparison of Normal Limits Arising in Nerve Conduction Studies
}

\author{
M.G. Campbell, E.P. Copp, ${ }^{*}$ J.L. James $\dagger$, J. Keenan,* \\ P.H. Merry $\ddagger$ and S.M. Rudolfer \\ Research Associate, Postgraduate Regional Institute of Medicine \\ and Dentistry, University of Newcastle upon Tyne, \\ * Consultant in Physical Medicine, Manchester Royal \\ Infirmary, † Consultant Physician, St. Luke's Hospital, \\ Huddersfield, ‡Consultant in Rheumatology and \\ Rehabilitation, Withington Hospital, Manchester, and \\ §Lecturer in Mathematical Statistics, University of \\ Manchester, U.K.
}

\begin{abstract}
Campbell, M.G., Copp, E.P., James, J.L., Keenan, J., Merry, P.H. and Rudolfer, S.M. A Comparison of Normal Limits Arising in Nerve Conduction Studies. Tohoku J. exp. Med., 1982, 137 (3), 261-267— A detailed study has been carried out on the influence of various factors, including sex of the patient and side examined, on normal values in peripheral nerve conduction studies. Patients were selected from three clinics, thereby enabling comparisons not only to be made within clinics but also between clinics. - ... nerve conduction studies; median nerve; ulnar nerve; lateral popliteal nerve
\end{abstract}

An essential and preliminary part of diagnosis is to obtain and process a 'training set' or data on which to base the diagnostic criteria of 'normality' and 'pathology'. Clinicians initially rely on published data of others, but with experience they build up their own data base. It is now possible to undertake the analysis of large data bases which would have been impossible before the advent of computers. The present paper has grown out of preliminary data-sorting required for our project on the applications of statistical methodology to electrodiagnosis. In order to make maximal use of a given data base, it is essential to be able to pool as many observations as possible when deriving normal values. We have made a detailed analysis of several factors which might be thought to influence normal values, comparing the three clinics which are participating in the project.

\section{Methods}

Methods of nerve conduction examination

Table 1 gives details of the machines used by the electrodiagnosticians and their inter-electrode distances for bipolar motor nerve stimulating electrodes and sensory nerve recording electrodes.

Received for publication, September 9, 1981. 
TABLE 1. Machines and bipolar inter-electrode distances

\begin{tabular}{|c|c|c|c|c|}
\hline \multirow{2}{*}{ Electrodiagnostician } & \multirow{2}{*}{ Hospital } & \multirow{2}{*}{ Machine } & \multicolumn{2}{|c|}{$\begin{array}{l}\text { Bipolar inter-electrode distances } \\
\qquad(\mathrm{cm})\end{array}$} \\
\hline & & & $\begin{array}{l}\text { Motor stimulating } \\
\text { electrodes }\end{array}$ & $\begin{array}{l}\text { Sensory recording } \\
\text { electrodes }\end{array}$ \\
\hline $\begin{array}{l}\text { Dr. E.P. Copp and } \\
\text { Dr. J. Keenan }\end{array}$ & $\begin{array}{l}\text { Manchester } \\
\text { Royal } \\
\text { Infirmary }\end{array}$ & Medelec MS6 & 1.6 & 2.0 \\
\hline Dr. J.L. James & $\begin{array}{l}\text { St. Luke's } \\
\text { Hospital, } \\
\text { Huddersfield }\end{array}$ & $\begin{array}{l}\text { American Electronics } \\
\text { Laboratories } \\
\text { stimulator with } \\
\text { Tektronix display } \\
\text { unit }\end{array}$ & 3.8 & 3.8 \\
\hline Dr. P.H. Merry & $\begin{array}{l}\text { Withington } \\
\text { Hospital } \\
\text { Manchester }\end{array}$ & Medelec MS6 & 1.7 & 3.8 \\
\hline
\end{tabular}

Motor nerve studies. All four electrodiagnosticians use basically the same technique.

Dr. Copp, Dr. Keenan and Dr. Merry place or strap an earth at the back of the hand for median and ulnar motor nerve studies and at the ankle for lateral popliteal motor nerve studies. Dr. James straps an earth to the upper arm for motor studies of all three nerves.

A coaxial concentric needle electrode (CNE) is inserted into a distal muscle innervated by the nerve being studied to record electrical responses. In the median nerve, Dr. Merry records from opponens pollicis, while the others record from abductor pollicis brevis. In the ulnar nerve, Dr. Copp and Dr. Keenan record from first dorsal interosseus, the other doctors recording from abductor digiti minimi. In the lateral popliteal nerve, all four record from extensor digitorum brevis.

An electrical stimulus is applied using a bipolar electrode at two sites along the course of the nerve proximal to the CNE. In the median nerve, the electrodiagnosticians stimulate at the level of the wrist and at the level of the elbow. In the ulnar nerve, they stimulate at the level of the wrist and above the elbow. In the lateral popliteal nerve, all four stimulate distally at the level of the ankle. Dr. James and Dr. Merry stimulate proximally at the neck of the fibula, the others stimulating at the level of the knee. The response in the distal muscle is picked up by the CNE, amplified and displayed on a CRO screen.

The motor latency at each site is defined as the time to the first deffection from the base line of the trace, measured to the nearest $0.1 \mathrm{msec}$. The distance $d$ between the sites for each nerve is taken as the distance between stimulating cathodes measured along the course of the nerve to the nearest $0.5 \mathrm{~cm}$. The motor conduction velocity $v$ in $\mathrm{m} / \mathrm{sec}$ is calculated as

$$
v=(d \times 10) /\left(t_{2}-t_{1}\right)
$$

where $t_{1}$ is the latency in msec at the distal site and $t_{2}$ is the latency in msec at the proximal site, $v$ being rounded off to the nearest $\mathrm{m} / \mathrm{sec}$.

Sensory nerve studies. Dr. Copp and Dr. Keenan place an earth at the back of the hand. For the median nerve, the index finger is stimulated using ring electrodes, with the cathode as near to the base of the finger as possible and the anode between the distal and proximal interphalangeal joints. For the ulnar nerve, the little finger is stimulated using ring electrodes positioned as above. The response is recorded using a bipolar saddle recording electrode strapped over the appropriate nerve at the level of the wrist with the cathode proximal to the anode.

Dr. Merry straps an earth to the back of the hand. He uses the same method of stimulation as Dr. Copp and Dr. Keenan, but with the positions of the cathode and anode reversed for both the stimulating ring electrodes and recording saddle electrodes. 
Dr. James uses a different stimulating technique. An earth is strapped to the upper arm. For the median nerve, the thumb and first three fingers are stimulated using pairs of clipped-on electrodes in parallel. For the ulnar nerve, all four fingers are stimulated. The response is picked up by a bipolar recording electrodes trapped over the appropriate nerve at the level of the wrist, and the polarity of the stimulating electrodes is altered as necessary by a switch to find the best evoked potential.

Dr. Copp, Dr. Keenan and Dr. Merry measure sensory latency as the time to the initial negative peak of deffection from the base line, whereas Dr. James measures to the onset of the initial negative deffection. All four measure sensory amplitude as the height of the negative deflection above the base line.

For more details of electrodiagnostic techniques and electrodiagnosis, see Lenman and Ritchie (1970).

\section{Normal limits}

In order to establish whether a nerve conduction finding is 'normal' or 'abnormal', it is necessary for the electrodiagnostician to examine the distribution of the finding in 'normal' patients. The selection of such patients is described later. Let such a finding be denoted by $X$. It is usually assumed that $X$ has a Gaussian distribution with mean $\mu$, variance $\sigma^{2}$. The problem of misdiagnosis of a nerve conduction finding is akin to the statistical problem of errors in hypothesis testing. Two mistaken diagnoses are here possible; false positive (declare finding abnormal when in fact it is normal) and false negative (the converse). It is the diagnostician's aim to control these errors as much as possible. Since 'abnormality' covers a very wide range of possible distributions of $X$ (i.e. values of $\mu$ and $\sigma^{2}$ ), whereas 'normality' is considered to be a single distribution, the only tractable approach is to control the probability of false positives [see, for example, Lusted (1968)]. A normal limit of $X$ is defined to be that value such that the probability of $X$ being more extreme (abnormal) than this value is roughly $0.025\left(2 \frac{1}{2} \%\right)$. The value of $2 \frac{1}{2} \%$ is conventional, and simplifies the calculations, since upper normal limits (UNL) are given by $\mu+2 \sigma$, lower normal limits (LNL) by $\mu-2 \sigma$. This is because the probability that $X>\mu+2 \sigma$ is 0.0228 , whereas the probability that $X<\mu-2 \sigma$ is 0.0228 . Findings taking UNL are latencies and latency differences; those using LNL are amplitudes and conduction velocities. Since $\mu$ and $\sigma^{2}$ are unknown, they are estimated, respectively, by the sample mean $\bar{x}=\frac{1}{n} \sum_{1}^{n} x_{i}$ and variance $s^{2}=\frac{1}{n-1} \sum_{1}^{n}\left(x_{i}-\bar{x}\right)^{2}$, where $x_{1}, \cdots, x_{n}$ are the findings in the sample considered. Thus, the UNL is calculated as $\bar{x}+2 s$, and LNL as $\bar{x}-2 s$, where the sample is taken over appropriate patients. We note that the normal limit approach is adopted by Buchthal and Rosenfalck (1966), for example, who give $5 \%$ and $2 \%$ normal limits.

\section{Factors which may influence normal limits}

In order to obtain a maximal data base for the computation of normal limits from a given set of patients' records, it is essential to assess the influence of various factors, of which we have considered the following:

TABLE 2. Distribution of patients in data base

\begin{tabular}{|c|c|c|c|c|}
\hline Clinic & Years & Males & Females & Total \\
\hline Dr. Copp & 1976 & 151 & 140 & 291 \\
\hline Dr. Keenan & 1976 & 195 & 204 & 399 \\
\hline M.R.I. & 1976 & 346 & 344 & 690 \\
\hline Dr. James & $1974-1977$ & 295 & 378 & 673 \\
\hline Dr. Merry & $1974-1977$ & 219 & 250 & 469 \\
\hline Total & & 860 & 972 & 1,832 \\
\hline
\end{tabular}


TABLE 3. Normal limits in

Finding

Median motor latency

$$
\text { Wrist }
$$

Median motor latency Elbow

Median motor latency Diff. elbow-wrist

Median motor velocity Elbow-wrist

Median sensory latency

Antilog (Median sensory log-amplitude)

Finding

Ulnar motor latency Wrist

Ulnar motor latency Above elbow

Ulnar motor latency Diff. above elbow-wrist

Ulnar motor velocity

Above elbow-wrist

Ulnar sensory latency

Antilog (Ulnar sensory logamplitude)

\section{Finding}

Lateral popliteal motor latency Ankle

Lateral popliteal motor latency Knee*

Lateral popliteal motor latency Diff. knee-ankle*

Lateral popliteal motor velocity Knee-ankle*
Dr. Copp and Dr. Keenan

$\begin{array}{lcc}\text { Class } & \begin{array}{c}\text { Number } \\ \text { of nerves }\end{array} & \text { Normal limit } \\ \text { NAD } & 196 & 4.5 \mathrm{msec} \\ \text { NAD } & 192 & 9.3 \mathrm{msec} \\ \text { NAD } & 192 & 5.4 \mathrm{msec} \\ \text { NAD } & 121 & 42 \mathrm{~m} / \mathrm{sec} \\ \text { NAD } & 213 & 3.4 \mathrm{msec} \\ \text { NAD } & 213 & 12 \mu \mathrm{V}\end{array}$

Notes: M, males only; F, females only;

TABLE 4. Normal limits in

Dr. Copp and Dr. Keenan

\begin{tabular}{|c|c|c|}
\hline Class & $\begin{array}{l}\text { Number } \\
\text { of nerves }\end{array}$ & Normal limit \\
\hline Overall & 201 & $4.6 \mathrm{msec}$ \\
\hline Overall $\mathrm{M}$ & 75 & $11.3 \mathrm{msec}$ \\
\hline $\mathrm{F}$ & 110 & $9.8 \mathrm{msec}$ \\
\hline Overall M & 75 & $6.9 \mathrm{msec}$ \\
\hline $\mathrm{F}$ & 110 & $5.9 \mathrm{msec}$ \\
\hline Overall & 125 & $45 \mathrm{~m} / \mathrm{sec}$ \\
\hline NAD & 177 & $3.2 \mathrm{msec}$ \\
\hline NAD & 177 & $7 \mu \mathrm{V}$ \\
\hline
\end{tabular}

Notes: M, males only; F, females only;

Table 5. Normal limits in lateral

Dr. Copp and Dr. Keenan

\begin{tabular}{|c|c|c|}
\hline Class & $\begin{array}{l}\text { Number } \\
\text { of nerves }\end{array}$ & Normal limit \\
\hline NAD & 91 & $7.2 \mathrm{msec}$ \\
\hline NAD M & 45 & $16.4 \mathrm{msec}$ \\
\hline $\mathrm{F}$ & 45 & $15.5 \mathrm{msec}$ \\
\hline NAD & 90 & $10.3 \mathrm{msec}$ \\
\hline NAD & 87 & $36 \mathrm{~m} / \mathrm{sec}$ \\
\hline
\end{tabular}

Notes: M, males only; F, females only; Overall, NAD and PNL combined. 
median nerve conduction studies

$$
\text { Dr. James }
$$

$\begin{array}{ccc}\text { Class } & \begin{array}{c}\text { Number } \\ \text { of nerves }\end{array} & \text { Normal limit } \\ \text { Overall } & 449 & 4.1 \mathrm{msec} \\ & & 9.2 \mathrm{msec} \\ \text { Overall M } & 152 & 8.4 \mathrm{msec} \\ \text { F } & 297 & 5.6 \mathrm{msec} \\ \text { Overall M } & 152 & 4.9 \mathrm{msec} \\ \text { F } & 297 & 45 \mathrm{~m} / \mathrm{sec} \\ \text { Overall } & 449 & 3.0 \mathrm{msec} \\ & & 14 \mu \mathrm{V}\end{array}$

Dr. Merry

Class $\begin{gathered}\text { Number } \\ \text { of nerves }\end{gathered}$

$\begin{array}{lll}\text { Overall } & 67 & 4.8 \mathrm{msec}\end{array}$

$\begin{array}{lll}\text { Overall M } & 11 & 9.8 \mathrm{msec}\end{array}$

$\begin{array}{lll}\mathrm{F} & 56 & 9.0 \mathrm{msec}\end{array}$

$\begin{array}{lll}\text { Overall M } & 11 & 5.5 \mathrm{msec}\end{array}$

$\mathrm{F} \quad 56 \quad 4.8 \mathrm{msec}$

Overali $\quad 67 \quad 43 \mathrm{~m} / \mathrm{sec}$

NAD $\quad 71 \quad 4.7 \mathrm{msec}$

NAD $71 \quad 6 \mu \mathrm{V}$

Overall, NAD and PNL combined.

ulnar nerve conduction studies

$$
\text { Dr. James }
$$

\begin{tabular}{|c|c|c|c|c|c|}
\hline Class & $\begin{array}{l}\text { Number } \\
\text { of nerves }\end{array}$ & Normal limit & Class & $\begin{array}{l}\text { Number } \\
\text { of nerves }\end{array}$ & Normal limit \\
\hline Overall & 435 & $2.9 \mathrm{msec}$ & Overall & 51 & $3.8 \mathrm{msec}$ \\
\hline Overall $\mathrm{M}$ & 171 & $9.7 \mathrm{msec}$ & Overall M & 16 & $10.9 \mathrm{msec}$ \\
\hline $\mathrm{F}$ & 264 & $8.3 \mathrm{msec}$ & $\mathrm{F}$ & 34 & $10.3 \mathrm{msec}$ \\
\hline Dverall M & 171 & $7.2 \mathrm{msec}$ & Overall $\mathrm{M}$ & 16 & $7.9 \mathrm{msec}$ \\
\hline $\mathrm{F}$ & 264 & $6.0 \mathrm{msec}$ & $\mathrm{F}$ & 34 & $10.3 \mathrm{msec}$ \\
\hline Dverall & 435 & $40 \mathrm{~m} / \mathrm{sec}$ & Overall & 50 & $44 \mathrm{~m} / \mathrm{sec}$ \\
\hline NAD & 23 & $3.3 \mathrm{msec}$ & NAD & 63 & $4.2 \mathrm{msec}$ \\
\hline NAD & 23 & $6 \mu \mathrm{V}$ & NAD & 64 & $5 \mu \mathrm{V}$ \\
\hline
\end{tabular}

Dr. Merry

Overall, NAD and PNL combined.

popliteal nerve conduction studies

$$
\text { Dr. James }
$$

\begin{tabular}{|c|c|c|}
\hline Overall & 101 & $6.1 \mathrm{msec}$ \\
\hline Overall & 101 & $15.4 \mathrm{msec}$ \\
\hline Overall $\mathrm{M}$ & 55 & $10.5 \mathrm{msec}$ \\
\hline F & 46 & $9.4 \mathrm{msec}$ \\
\hline Overall & 101 & $36 \mathrm{~m} / \mathrm{sec}$ \\
\hline
\end{tabular}

Class $\begin{gathered}\text { Number } \\ \text { of nerves }\end{gathered}$

Dr. Merry

Class

NAD

Number of nerves

Normal limit

$\begin{array}{lr}15 & 7.1 \mathrm{msec} \\ 15 & 14.0 \mathrm{msec} \\ 15 & 8.6 \mathrm{msec} \\ 15 & 35 \mathrm{~m} / \mathrm{sec}\end{array}$

* For Dr. Merry and Dr. James, replace 'knee' by 'neck of fibula'. 
Class. This relates to the question of whether a localised peripheral nerve lesion has an effect on the other peripheral nerves in the ipsilateral limb. If there is no such effect, then the observed values for the latter nerves can be included in the calculation of "normal' values. For any nerve conduction finding we thus take two classes of patient; those in whom no electrodiagnostic abnormality was detected or who had a localised peripheral nerve lesion on the contralateral side (NAD), and those who had a localised peripheral nerve lesion on the ipsilateral side but not in the nerve under consideration (PNL).

Sex. Males and females tend to differ in the lengths of their limbs, and we would expect longer latencies and latency differences in men. Is the difference between the sexes sufficiently large to prevent the pooling of male and female normal values?

Side. Pending evidence to the contrary, each patient was considered as having two independent sides (within the diseases classes considered). Provided the inclusion criteria were satisfied and the data were available, it can be asked whether normal values obtained on one side of a patient differ significantly from those obtained on the other. We note that the nerve conduction findings tended to be marginally less 'normal' on the right side. This is probably connected with the fact that the right side is dominant in the majority of patients and hence suffers more wear and tear.

Age had to be omitted as a factor since Dr. James was the only doctor consistently recording the patient's age. It should be pointed out that the effect of age upon normal values of sensory conduction velocities and amplitudes is generally recognised [see, for example, Appendices X-XII in Rémond (1975)]. Patients were excluded from the study if their age was recorded and less than 18 or over 65 .

\section{Data base}

Data have been collected from the EMG clinics of Dr. Copp and Dr. Keenan at Manchester Royal Infirmary, Dr. James at St. Luke's Hospital, Huddersfield, and Dr. Merry at Withington Hospital, Manchester, and have been coded and stored on the Joint System at the University of Manchester Regional Computer Centre. Table 2 gives the distribution of patients' records by clinic, year and sex.

Patients in this complete set were excluded from the present study if (i) the patient's age was given as under 18 or over 65 (patients whose age was not stated were included, thereby introducing a slight bias due to some patients whose unstated age was not between 18 and 65); (ii) the EMG diagnosis was other than NAD or PNL as defined above; (iii) there were at least two localised peripheral nerve lesions present; (iv) the motor nerve conduction velocities lay outside the range 35-90 m/sec in the median and ulnar nerves or 30$70 \mathrm{~m} / \mathrm{sec}$ in the lateral popliteal nerve. These were obtained from the electrodiagnosticians, in whose experience observations outside these ranges were of doubtful quality.

\section{Choice of pooled normal limits}

Analysis of variance [see, for example, Armitage (1971)] was used as a preliminary tool to examine the various normal limits, which were then pooled or kept separate on the grounds of clinical significance (would keeping separate normal limits substantially affect the clinicians' diagnoses ?), bearing in mind also the inconvenience of having too many tables of normal values to consult.

\section{Results}

These are summarised in Tables 3,4 and 5 .

It turned out in most cases that it was not satisfactory to use PNL cases for normal limits in the contralateral nerve, presumably because there is some interaction between the nerve examined and the contralateral nerve. This was particularly the case with sensory latencies and amplitudes. The electrodiagnosticians consider amplitude to be more sensitive diagnostically than latency. In fact, values of the amplitudes amongst the nerves accepted for the study tended 
to be more normal than the corresponding latencies. It was very clear that PNL's tended to have impaired sensory findings.

Differences between the sexes were most marked with motor latencies and latency differences where a longer length of nerve was involved. This is not surprising, since men have longer limbs on average than women. Corresponding motor velocities, which are 'distance corrected', could be pooled, although females tended to have slightly faster velocities than males.

Nowhere did the side of the patient alter the normal values substantially, and hence the side of the patient is not deemed to influence the corresponding normal values.

\section{Acknowledgments}

The results reported here will form part of M.G. Campbell's Ph. D. thesis, for which the financial support provided by the Science Research Council and West Kirklees Area Health Authority is gratefully acknowledged.

\section{References}

1) Armitage, P. (1971) Statistical Methods in Medical Research, Blackwell, Oxford.

2) Buchthal, F. \& Rosenfalck, A. (1966) Evoked action potentials and conduction velocity in human sensory nerves. Brain Res., 3, 1-122.

3) Lenman, J.A.R. \& Ritchie, A.E. (1970) Clinical Electromyography, Pitman Medical, London.

4) Lusted, L.B. (1968) Introduction to Medical Decision Making, Charles C. Thomas, Springfield, Illinois.

5) Rémond, A. (1975) (Editor-in-Chief) Handbook of Electroencephalography and Clinical Neurophysiology, 16 A Electromyography: Nervous and Muscular Evoked Potentials, Elsevier, Amsterdam. 